Western University

Scholarship@Western

$6-2020$

\title{
Dissection of Anoplophora glabripennis (Coleoptera: Cerambycidae) larval tissues for physiological and molecular studies
}

\author{
Alex S. Torson \\ Western University, atorson@uwo.ca \\ Lauren E. Des Marteaux \\ Western University, Idesmart@uwo.ca \\ Susan Bowman \\ Great Lakes Forestry Centre \\ Meng Lei Zhang \\ Western University \\ Kevin Ong \\ Western University, kong7@uwo.ca
}

See next page for additional authors

Follow this and additional works at: https://ir.lib.uwo.ca/biologypub

Part of the Biology Commons

\section{Citation of this paper:}

Torson, Alex S.; Des Marteaux, Lauren E.; Bowman, Susan; Zhang, Meng Lei; Ong, Kevin; Doucet, Daniel; Sinclair, Brent J; and Roe, Amanda D., "Dissection of Anoplophora glabripennis (Coleoptera: Cerambycidae) larval tissues for physiological and molecular studies" (2020). Biology Publications. 109. https://ir.lib.uwo.ca/biologypub/109 


\section{Authors}

Alex S. Torson, Lauren E. Des Marteaux, Susan Bowman, Meng Lei Zhang, Kevin Ong, Daniel Doucet, Brent J Sinclair, and Amanda D. Roe 
The Canadian Entomologist

\title{
Dissection of Anoplophora glabripennis (Coleoptera: Cerambycidae) larval tissues for physiological and molecular studies
}

\begin{abstract}
Alex S. Torson*1, Lauren E. Des Marteaux ${ }^{1,2, a}$, Susan Bowman ${ }^{3}$, Meng Lei Zhang ${ }^{1}$, Kevin Ong $^{1}$, Daniel Doucet ${ }^{3}$, Brent J. Sinclair ${ }^{1}$, Amanda D. Roe ${ }^{3}$
\end{abstract}

\footnotetext{
${ }^{1}$ Department of Biology, University of Western Ontario, 1151 Richmond St., London, Ontario, N6A 3K7, Canada
}
${ }^{2}$ Institute of Entomology, Biology Centre of the Academy of Sciences of the Czech Republic, Branišovská 1160/31, České Budějovice, 37 005, Czech Republic
${ }^{3}$ Great Lakes Forestry Centre, Natural Resources Canada, Canadian Forest Service, 1219 Queen St., Sault Ste. Marie, Ontario P6A 2E5, Canada

${ }^{a}$ Graduate School of Science, Osaka City University, 3-3-138 Sugimoto Sumiyoshi-ku, Osaka, 558-8585, Japan

* Corresponding author: Alex S. Torson: atorson@uwo.ca 


\section{Abstract}

2 Many biological processes are partitioned among organs and tissues, necessitating tissue-specific

3 or organ-specific analysis (particularly for comparative -omics studies). Standardised techniques

4 for tissue identification and dissection are therefore imperative for comparing among studies. Here

5 we describe dissection protocols for isolating six key tissues/organs from larvae of the Asian

6 longhorned beetle, Anoplophora glabripennis (Motschulsky) (Coleoptera: Cerambycidae): the

7 supraoesophageal ganglion, posterior midgut, hindgut, Malpighian tubules, fat body, and thoracic

8 muscle. We also describe how to extract haemolymph and preserve whole larvae for measurements

9 such as protein, lipid, and carbohydrate content. We include dissection protocols for both fresh-

10 killed and previously frozen specimens. Although this protocol is developed for A. glabripennis,

11 it should allow standardised tissue collection from larvae of other cerambycids and be readily

12 transferrable to other beetle taxa with similar larval morphology.

\section{Résumé}

15 Les processus physiologiques et moléculaires ont cours au sein de différents tissus, ce qui nécessite

16 pour chacun des analyses distinctes, en particulier dans le cadre d'études «omiques» comparées.

17 Il est donc impératif de standardiser les techniques de dissection et les protocoles d'identification

18 des tissus pour comparer des études. Nous décrivons ici les protocoles de dissection pour isoler six

19 tissus ou organes clés de larves du longicorne asiatique Anoplophora glabripennis (Motschulsky)

20 (Coleoptera: Cerambycidae), soient le ganglion supraoesophagien, l'intestin moyen, le tube

21 digestif postérieur, les tubules de Malpighi, le corps gras et les muscles thoraciques. Nous

22 décrivons également comment extraire l'hémolymphe et conserver les larves entières pour

23 effectuer des mesures de teneur en protéines, en lipides et en glucides. Nous incluons des 
24 protocoles de dissection non seulement pour les échantillons frais, mais aussi pour les échantillons 25 congelés, afin d'aider les chercheurs qui n'ont pas accès à des spécimens vivants. Bien que ces 26 protocoles aient été élaborés pour A. glabripennis, ils devraient permettre de standardiser la 27 collecte de tissus chez les larves d'autres cérambycidés, et être aisément transférables à d'autres 28 taxons de coléoptères avec une morphologie larvaire similaire 


\section{Introduction}

30 Insects maintain homeostasis via integrated physiological systems with a division of labour

31 among tissues (Klowden 2013). Thus, most physiological processes should be explored at the

32 tissue level; for example, the midgut is usually the focus of digestion and absorption studies

33 (Caroci and Noriega 2003; Jagadeshwaran et al. 2010), while the Malpighian tubules are normally

34 responsible for excretion (Dow et al. 1998). However, many transcriptomic studies analyse

35 homogenised whole insects (e.g., Teets et al. 2012; Poupardin et al. 2015; MacMillan et al. 2016;

36 Torson et al. 2017; Koniger and Grath 2018), and thus do not capture tissue-specific processes,

37 which may be important. For example, upregulated sodium pump expression in the Malpighian

38 tubules would likely reduce primary urine production, while a similar upregulation in the hindgut

39 would likely enhance water reabsorption to the haemolymph. The physiological implications of

40 these two scenarios would not be predicted from a whole-animal homogenate (Des Marteaux et

41 al. 2017, 2018).

42 Shifting from whole animal to tissue-specific analyses must be done carefully, as

43 inconsistencies in dissection technique or inadvertent inclusion of non-target tissues (e.g.,

44 inclusion of fat traces with gut samples) can lead to misleading results. Furthermore, tissues,

45 organs, and organ systems may be improperly homologised. For example, the large, anterior

46 portion of the midgut in cerambycid larvae has been misinterpreted as belonging to the foregut

47 (Wei et al. 2006; Choo et al. 2007), likely leading to spurious reports of chitinase and cellulase

48 enzymes occurring in the foregut. Thus, it is important to standardise dissection and sample

49 preparation protocols to ensure comparable results across samples within a study as well as among

50 studies on the same or related species. Such standardised tissue classification (and developmental 
51 staging) protocols are de rigeur for model organisms (e.g., Sinha 1958; Eaton 1974; Bainbridge

52 and Bownes 1981; Goodman et al. 1985; Curtis et al. 1999).

53 Some cerambycid (longhorned) beetles are important forest pests (Eyre and Haack 2017).

54 Asian longhorned beetle (Anoplophora glabripennis Motschulsky; Coleoptera: Cerambycidae:

55 Lamiinae) larvae feed on healthy tree tissues across a broad host range (Faccoli et al. 2016) and

56 this species has been inadvertently introduced in North America and Europe (Nehme et al. 2010;

57 Dodds and Orwig 2011; Hull-Sanders et al. 2017). As with many economically important invasive

58 species, the physiology and molecular biology of Asian longhorned beetle is the focus of current

59 studies in multiple laboratories and countries. Thus, standardised dissection methods (currently

60 unavailable for any cerambycid) are required to ensure appropriate tissue/organ identification and

61 consistent sampling and comparisons.

62 Here we present a protocol for collecting haemolymph and dissecting six tissues/organs (the

63 supraoesophageal ganglion, posterior midgut, hindgut, Malpighian tubules, fat body, and thoracic

64 muscle) from Asian longhorned beetle larvae, distinguishing the appearance of the tissues in fresh

65 and previously frozen specimens. This protocol should facilitate consistency among studies of

66 Asian longhorned beetle and other cerambycid larvae and be useful for other beetles with similar

67 larval morphology.

68

\section{Protocol}

70 Asian longhorned beetle larvae used in the present study originated from a laboratory colony

71 derived from the Chicago (Illinois, United States of America) infestation, and were reared under

72 quarantine (Canadian Food Inspection Agency authorisation WA-2013-017) at the Insect

73 Production and Quarantine Laboratory at the Great Lakes Forestry Centre (stock number: 
74 Glfc:IPQL:AglaUIC01; Great Lakes Forestry Centre, Sault Ste. Marie, Ontario, Canada) (Roe et 75 al. 2018). We reared larvae at $25^{\circ} \mathrm{C}$ under constant darkness for 10 weeks and then exposed them

76 to $7^{\circ} \mathrm{C}$ to induce a developmental arrest (Keena and Moore 2010). We sampled all larvae during

77 this developmental arrest. We dissected live larvae at the Great Lakes Forestry Centre and freeze-

78 killed larvae at the University of Western Ontario in London, Ontario. Freeze-killed larvae had

79 been flash-frozen in liquid nitrogen at the Great Lakes Forestry Centreand thereafter stored at -80

$80{ }^{\circ} \mathrm{C}$ until shipping to the University of Western Ontario on dry ice.

\section{External larval anatomy}

83 Asian longhorned beetle larvae are large, reaching up to $50 \mathrm{~mm}$ in length and weighing more

84 than $1 \mathrm{~g}$ (Keena and Moore 2010). The external anatomy of the cylindrical, cream-coloured larvae

85 (Fig. 1) has been described in detail elsewhere (Cavey et al. 1998) and is similar to that of other

86 cerambycid larvae (Svacha and Lawrence 2014). The head is heavily sclerotised, prognathous, and

87 partially retracted. The prothorax (Fig. 1: $\mathrm{t} 1$ ) is expanded relative to the mesothoracic and

88 metathoracic segments (Fig. 1: t2 and t3) and has a partially-sclerotised pronotum. The

89 mesothoracic spiracle is well developed and there are functional spiracles on the first eight

90 abdominal segments (Fig. 1: a1-a8). The larvae lack both thoracic legs and abdominal prolegs: the

91 virtual absence of thoracic legs distinguishes Lamiinae from other cerambycid subfamilies which

92 (except for some Cerambycinae) have segmented legs.

93

\section{Haemolymph extraction}

95 Prior to dissection, we punctured the anterior edge of the prothoracic shield cuticle of live

96 larvae with a 22-gauge 1-inch needle (Thermo Fisher Scientific; Sunnyvale, California, United 
97 States of America) to create a bleeding wound (Fig. 2). We held the larva over a $1.5-\mathrm{mL}$ tube to

98 collect the haemolymph. The total volume of extracted haemolymph varied from $90-300 \mu \mathrm{L}$

99 among individuals due to variation in larval size. We centrifuged the collected haemolymph for 3

100 seconds at $2000 \times g$ to separate the haemolymph (infranatant) from lipids (supernatant) and other

101 debris (high-density fraction). We used this low spin force to avoid separating haemocytes from

102 the plasma of the haemolymph. We aliquoted known quantities of haemolymph for biochemical

103 analyses into 1.5-mL microcentrifuge tubes and flash-froze them in liquid nitrogen. Evaporation

104 should be minimised for some applications, such as measuring haemolymph osmolality. In these

105 cases, we covered the haemolymph with a layer of mineral oil (M5904, Sigma-Aldrich,Oakville,

106 Ontario, Canada) before freezing to reduce evaporation. Haemolymph will begin to melanise after

10715 minutes (Fig. 2B), so it must be processed quickly. Because freezing damages tissue and

108 perturbs homeostasis, hemolymph from previously-frozen larvae is probably not physiologically-

109 relevant, so while extracted hemolymph can be frozen, we do not recommend extracting 110 hemolymph from previously-frozen larvae.

\section{Internal anatomy and dissection}

113 Larval dissection. We dissected larvae in a dark-bottomed Sylgard-lined dish (Living Systems

114 Instrumentation; Saint Albans City, Vermont, United States of America) that was deep enough

115 (approximately $3 \mathrm{~cm}$ ) to submerge the entire body in dissection media of choice (examples

116 below). We pinned the larvae through the sides of the prothorax (Fig. 1: t1) and the last

117 abdominal segment (Fig. 1: a10) to hold it ventral side-down with the body straight and the

118 cuticle taut. We then cut through the cuticle along the dorsal midline anteriorly using

119 microscissors held with the blades angled dorsally to avoid puncturing the gut. We spread the 
120 body walls laterally with 8-10 additional pins to open the body cavity and expose the internal

121 organs (Fig. 3). To relax the tissues for easier dissection, frozen larvae were thawed and

122 submerged in an aqueous solution chosen based on specific downstream needs (e.g., water,

123 Ringer's, or insect saline). Submerging fresh (unfrozen) specimens entirely in solution caused

124 the fat body to dislodge and obscure other tissues, therefore we pipetted 1-2 $\mathrm{mL}$ of an aqueous

125 solution (as above) into the opened body cavity to wash away the fat body and relax the tissues

126 of fresh specimens. We placed sampled tissues in a drop of fresh saline on a sterile Petri dish and

127 cleared the samples of fat body and large (readily visible) tracheae and nervous tissue prior to

128 flash-freezing in microcentrifuge tubes.

129

130 Fat body, Malpighian tubules, and gut. The fat body occupies much of the larval internal

131 cavity and obscures many internal organs, although the gut (orange or green in colour) is

132 typically at least partly visible. We collected fat body samples from three areas: the lateral

133 regions of the prothorax (Fig. 1: t3-a1); posterior midgut (Fig. 1: a4-a5); and hindgut (Fig. 1: a7-

134 a9). We removed a total of approximately 300-500 mg for metabolite analysis, then removed

135 and discarded all remaining fat body (an additional $300 \mathrm{mg}$ could easily be collected from a

136 medium-sized larva). Removing the remaining fat improves visibility of the gut and other organs

137 (Fig. 4).

138 We collected the Malpighian tubules prior to removing the gut. The Malpighian tubules (which 139 may be entangled in tracheae) attach at the bulbous midgut-hindgut intersection (Fig. 5). Because 140 cerambycid larvae have cryptonephridial Malpighian tubules, we collected the free regions of the 141 tubules prior to their entrance into the rectal wall. At this stage of the dissection there are critical 142 differences between fresh and freeze-killed specimens. For freeze-killed larvae, the gut may be 
143 pinned to one side away from the body to expose and isolate the Malpighian tubules. Multiple

144 tracheae must be severed to liberate the gut, and this should be done carefully to avoid damaging

145 the entwined Malpighian tubules (Fig. 5). Note that frozen larvae have white, rather than yellow,

146 Malpighian tubules. Although the Malpighian tubules and tracheae both appear white in frozen

147 larvae, the Malpighian tubules can be distinguished by their opaque, slightly flattened and

148 repeatedly curved (bumpy) appearance, while the tracheae, being internally supported by the

149 cuticular taenidia (visible with specific lighting and/or higher magnification), appear cylindrical,

150 hollow, shiny, and without repeated curves (Fig. 5). Although we could not pin the extremely

151 fragile midguts of fresh larvae to the side, the Malpighian tubules of fresh larvae were bright

152 yellow and therefore easily distinguishable from the tracheae. We used fine forceps to sever the

153 Malpighian tubules from the base at the hindgut-midgut intersection.

154 Morphological differences between the midgut and hindgut are clear in both fresh and frozen

155 specimens; the junction between the gut regions is identifiable by a decrease in diameter, 156 attachment of Malpighian tubules (Fig. 5) and (potentially) a change in colour (Fig. 4). To collect

157 the hindgut, we severed the midgut-hindgut junction with microscissors. We sampled the posterior 158 midgut by collecting a $2.0-2.5 \mathrm{~cm}$ section of gut anterior to the midgut-hindgut junction. After 159 dissecting each gut section, we cut open the section, removed the solid contents (food bolus) with 160 forceps, and then rinsed the tissue with fresh insect saline (note that a portion of the gut luminal 161 microbiota will likely remain in the gut folds). Inclusion of the gut contents for downstream 162 analyses (e.g., microbiome; Scully et al. 2014) can be achieved by clamping the gut closed at each 163 end prior to severing the tissue (see MacMillan and Sinclair 2011). 
165 Muscle. Large muscle bundles are found in the prothorax and attached to the body wall of each

166 thoracic and abdominal segment and are among the easiest tissue to sample. We sampled muscle

167 bundles within the prothorax (i.e., the main dorsal head retractor and pharyngeal muscles) (Fig. 6).

168 These firm, striated muscles are easily distinguishable from other musculature in both fresh and

169 frozen individuals. We used forceps or microscissors to remove prothoracic muscle (making cuts

170 away from the midline), being careful to avoid damaging the nervous tissue such as the

171 supraesophageal ganglia or nerve cord along the midline (see below).

172

173 Supraoesophageal ganglia. The brain (supraoesophageal ganglia) is comprised of two lobes

174 placed above the oesophagus within the sclerotized cranium, which is retracted beneath the

175 pronotum (Fig. 7). We used the oesophagus as a guide to locate the brain. First, we carefully

176 exposed the oesophagus by pushing the posterior cranial margin up and forward. This helps to

177 expose the brain, allowing access to it through the occipital foramen. To extract the brain, we

178 gently severed the circumoesophageal nerve ring with microscissors or forceps and removed the

179 brain with forceps.

180

181

\section{Discussion}

182

There are more than 36000 described Cerambycidae species (Monne et al. 2017). Consistent

183 dissection approaches, such as those outlined here, should facilitate tissue-specific physiological

184 and molecular research for Asian longhorned beetle and related cerambycids even for non-

185 morphologists. The large size of Asian longhorned beetle larvae allows tissue harvesting for

186 multiple purposes (e.g., samples destined for both physiological assays and genotyping), providing 
187 an opportunity to associate physiology with population genetic information; an approach that can

188 inform mechanistic species distribution models for invasive species (Buckley et al. 2010).

189 Haemolymph collection is perhaps the most time-dependent component of the protocol we

190 describe. Melanisation in Asian longhorned beetle is fairly fast, so haemolymph should be

191 sampled, processed, and stored within 15 minutes. Haemolymph samples destined for assays such

192 as haemocyte counts or metabolite concentrations can be flash frozen in liquid nitrogen. For other

193 downstream measurements (e.g., haemolymph osmolality), it is necessary to store the samples

194 under mineral/immersion oil or in a capillary tube to prevent evaporation. Note that freezing

195 disrupts cellular integrity, thus haemolymph collected from previously frozen specimens may

196 contain products from ruptured cells of various tissues. One potential solution to this problem

197 would be to centrifuge at a higher speed to remove cells and large cellular debris.

198 We expect this protocol to be generally applicable throughout Cerambycidae, although species-

199 specific differences in tissue size and appearance are likely. For example, because cerambycid

200 larvae range from approximately 5-200 $\mathrm{mm}$ in length (Lawrence 1991) we expect that tissues of

201 smaller individuals may be difficult to dissect and differentiate, and may not yield sufficient

202 material for some downstream applications (e.g., RNA-seq). In such cases, tissue samples from

203 multiple individuals can be pooled. Larval morphology among beetle families can vary

204 significantly, however the methods outlined here should be generalisable to families with similar 205 morphology to Cerambycidae.

\section{Acknowledgements}

208 We would like to thank the technical staff in the Insect Production and Quarantine Laboratories 209 at the Great Lakes Forestry Centre for their work in rearing specimens used for the development 
210 of this protocol. We would also like to thank Petr Švácha for lending his expertise to improve

211 earlier drafts of the manuscript. This work was supported by a Genome Canada, Genome British

212 Columbia, and Genome Quebec [LSARP 10106; Genome Canada] grant for the Biosurveillance

213 of Alien Forest Enemies (BioSAFE).

214

215

References

216

217

Bainbridge, S.P. and Bownes, M. 1981. Staging the metamorphosis of Drosophila melanogaster. Journal of Embryology and Experimental Morphology, 66: 57-80.

218

219

220

221

222

223

224

225

226

227

228

229

230

231

232

233

234

235

236

237

238

239

240

Buckley, L.B., Urban, M.C., Angilletta, M.J., Crozier, L.G., Rissler, L.J., and Sears, M.W. 2010. Can mechanism inform species' distribution models? Ecology Letters, 13: 1041-1054. https://doi.org/10.1111/j.1461-0248.2010.01479.x.

Caroci, A.S. and Noriega, F.G. 2003. Free amino acids are important for the retention of protein and non-protein meals by the midgut of Aedes aegypti females. Journal of Insect Physiology, 49: 839-844. https://doi.org/10.1016/S0022-1910(03)00134-3.

Cavey, J.F., Hoebeke, E.R., Passoa, S., and Lingafelter, S.W. 1998. A new exotic threat to North American hardwood forests: an Asian longhorned beetle, Anoplophora glabripennis (Motschulsky) (Coleoptera : Cerambycidae). I. Larval description and diagnosis. Proceedings of the Entomological Society of Washington, 100: 373-381.

Choo, Y.M., Lee, K.S., Kim, B.Y., Kim, D.H., Yoon, H.J., Sohn, H.D., and Jin, B.R. 2007. A gut-specific chitinase from the mulberry longicorn beetle, Apriona germari (Coleoptera: Cerambycidae): cDNA cloning, gene structure, expression and enzymatic activity. European Journal of Entomology, 104: 173-180. https://doi.org/10.14411/eje.2007.026.

Curtis, N.J., Ringo, J.M., and Dowse, H.B. 1999. Morphology of the pupal heart, adult heart, and associated tissues in the fruit fly, Drosophila melanogaster. Journal of Morphology, 240: 225-235. https://doi.org/10.3390/genes9120624.

Des Marteaux, L.E., Khazraeenia, S., Yerushalmi, G.Y., Donini, A., Li, N.G., and Sinclair, B.J. 2018. The effect of cold acclimation on active ion transport in cricket ionoregulatory tissues. Comparative Biochemistry and Physiology A, 216: 28-33. https://doi.org/10.1016/j.cbpa.2017.11.005.

Des Marteaux, L.E., McKinnon, A.H., Udaka, H., Toxopeus, J., and Sinclair, B.J. 2017. Effects of cold-acclimation on gene expression in fall field cricket (Gryllus pennsylvanicus) 
ionoregulatory tissues. BMC Genomics, 18: article 357, 1-17. https://doi.org/10.1186/s12864-017-3711-9.

Dodds, K.J. and Orwig, D.A. 2011. An invasive urban forest pest invades natural environments Asian longhorned beetle in northeastern US hardwood forests. Canadian Journal of Forest Research, 41: 1729-1742. https://doi.org/10.1139/X11-097.

Dow, J.A.T., Davies, S.A., and Sozen, M.A. 1998. Fluid secretion by the Drosophila Malpighian tubule. American Zoologist, 38: 450-460. https://doi.org/10.1093/icb/38.3.450.

Eaton, J.L. 1974. Nervous system of the head and thorax of the adult tobacco hornworm, Manduca sexta (Lepidoptera: Sphingidae). International Journal of Insect Morphology and Embryology, 3: 47-66. https://doi.org/10.1016/S0020-7322(74)81006-8.

Eyre, D. and Haack, R.A. 2017. Invasive cerambycid pests and biosecurity measures. In Cerambycidae of the world: biology and pest management, Edited by Q. Wang. CRC Press, Boca Raton, Florida, United States of America. Pp. 563-607.

Faccoli, M., Favaro, R., Concheri, G., Squartini, A., and Battisti, A. 2016. Tree colonization by the Asian longhorn beetle, Anoplophora glabripennis (Coleoptera: Cerambycidae): effect of habitat and tree suitability. Insect Science, 23: 288-296. https://doi.org/10.1111/17447917.12192.

Goodman, W.G., Carlson, R.O., and Nelson, K.L. 1985. Analysis of larval and pupal development in the tobacco hornworm (Lepidoptera, Sphingidae), Manduca sexta. Annals of the Entomological Society of America, 78: 70-80. https://doi.org/10.1093/aesa/78.1.70.

Hull-Sanders, H., Pepper, E., Davis, K., and Trotter, R.T. 2017. Description of an establishment event by the invasive Asian longhorned beetle (Anoplophora glabripennis) in a suburban landscape in the northeastern United States. Public Library of Science One, 12: e0181655. https://doi.org/10.1371/journal.pone.0181655.

Jagadeshwaran, U., Onken, H., Hardy, M., Moffett, S.B., and Moffett, D.F. 2010. Cellular mechanisms of acid secretion in the posterior midgut of the larval mosquito (Aedes aegypti). Journal of Experimental Biology, 213: 295-300. https://doi.org/10.1242/jeb.037549.

Keena, M.A. and Moore, P.M. 2010. Effects of temperature on Anoplophora glabripennis (Coleoptera : Cerambycidae) larvae and pupae. Environmental Entomology, 39: 13231335. https://doi.org/10.1603/En09369. 
Klowden, M.J. 2013. Physiological systems in insects. Elsevier/Academic Press, Amsterdam, The Netherlands.

Koniger, A. and Grath, S. 2018. Transcriptome analysis reveals candidate genes for cold tolerance in Drosophila ananassae. Genes, 9: article 624, 1-22. https://doi.org/10.3390/genes9120624.

Lawrence, J.F. 1991. Cerambycidae (Chrysomeloidea) (including Disteniidae, Hypocephalidae, Oxypeltidae, Parandridae, Spondylidae, Vesperiidae): long-horned beetles, round-headed wood borers. In Immature insects. Edited by F. W. Stehr. Kendall/Hunt Publishing, Dubuque, Iowa, United States of America. Pp. 556-561.

MacMillan, H.A., Knee, J.M., Dennis, A.B., Udaka, H., Marshall, K.E., Merritt, T.J.S., and Sinclair, B.J. 2016. Cold acclimation wholly reorganizes the Drosophila melanogaster transcriptome and metabolome. Scientific Reports, 6: article 28999. https://doi.org/10.1038/srep28999.

MacMillan, H.A. and Sinclair, B.J. 2011. The role of the gut in insect chilling injury: coldinduced disruption of osmoregulation in the fall field cricket, Gryllus pennsylvanicus. Journal of Experimental Biology, 214: 726-734. https://doi.org/10.1242/jeb.051540.

Monne, M.L., Monne, M.A., and Wang, Q. 2017. General morphology, classification, and biology of Cerambycidae. In Cerambycidae of the world: biology and pest management. Edited by Q. Wang. CRC Press, Boca Raton, Florida, United States of America. Pp. $2-$ 66.

Nehme, M., Keena, M., Zhang, A.J., Sawyer, A., and Hoover, K. 2010. Monitoring Asian longhorned beetles in Massachusetts. In Proceedings, 21st U.S. Department of Agriculture interagency research forum on invasive species. Edited by K.A. McManus and K.W. Gottschalk. United States Department of Agriculture, Forest Service, Newtown Square, Pennsylvania, United States of America. Pp. 109-110.

Poupardin, R., Schottner, K., Korbelova, J., Provaznik, J., Dolezel, D., Pavlinic, D., et al. 2015. Early transcriptional events linked to induction of diapause revealed by RNA-seq in larvae of drosophilid fly, Chymomyza costata. BMC Genomics, 16: article 720. https://doi.org/10.1186/s12864-015-1907-4.

Roe, A.D., Demidovich, M., and Dedes, J. 2018. Origins and history of laboratory insect stocks in a multispecies insect production facility, with the proposal of standardized nomenclature and designation of formal standard names. Journal of Insect Science, 18: 19. https://doi.org/10.1093/jisesa/iey037.

Scully, E.D., Geib, S.M., Carlson, J.E., Tien, M., McKenna, D., and Hoover, K. 2014. Functional genomics and microbiome profiling of the Asian longhorned beetle (Anoplophora 
Sinha, R.N. 1958. The alimentary canal of the adult of Tribolium castaneum Herbst (Coleoptera, Tenebrionidae). Journal of the Kansas Entomological Society, 31: 118-125. https://doi.org/10.1016/0020-7322(73)90014-7.

Svacha, P. and Lawrence, J.F. 2014. Cerambycidae Latreille. 1802. In Handbook of zoology Arthropoda: Insecta. Coleoptera, beetles, morphology and systematics. Edited by R.A.B. Leschen and R.G. Beutel. Walter de Gruyter, Berlin, Germany. Pp. 77-177.

Teets, N.M., Peyton, J.T., Ragland, G.J., Colinet, H., Renault, D., Hahn, D.A., and Denlinger, D.L. 2012. Combined transcriptomic and metabolomic approach uncovers molecular mechanisms of cold tolerance in a temperate flesh fly. Physiological Genomics, 44: 764777. https://doi.org/10.1152/physiolgenomics.00042.2012.

Torson, A.S., Yocum, G.D., Rinehart, J.P., Nash, S.A., Kvidera, K.M., and Bowsher, J.H. 2017. Physiological responses to fluctuating temperatures are characterized by distinct transcriptional profiles in a solitary bee. Journal of Experimental Biology, 220: 33723380. https://doi.org/10.1242/jeb.156695.

Wei, Y.D., Lee, K.S., Gui, Z.Z., Yoon, H.J., Kim, I., Je, Y.H., et al. 2006. N-linked glycosylation of a beetle (Apriona germari) cellulase Ag-EGase II is necessary for enzymatic activity. Insect Biochemistry and Molecular Biology, 36: 435-441. https://doi.org/10.1016/j.ibmb.2006.03.007. 
332 Figure 1. External larval anatomy of Anoplophora glabripennis. A, Dorsal view of the head (h), 333 pronotum, thoracic segments (t1-3), and abdominal segments (a1-10) B, lateral view.

335 Figure 2. Haemolymph collection from Anoplophora glabripennis larvae. A, A bleeding wound 336 was created by puncturing the anterior edge of the prothoracic shield; $\mathbf{B}$, fresh haemolymph (left) 337 and haemolymph that has melanised following 15 minutes exposure to air.

339 Figure 3. Open body cavity. Larval morphology of the head, prothorax, fat body, and gut in 340 Anoplophora glabripennis. A) Freeze killed; B, fresh killed.

342 Figure 4. Gut and associated structures. Foregut (blue), midgut (green), and hindgut (orange) of 343 Anoplophora glabripennis larvae after removal of surrounding fat body. A, freeze killed; B, fresh 344 killed.

346 Figure 5. Malpighian tubules and tracheae. Morphological differences between the Malpighian 347 tubules and tracheae in both freeze-killed and fresh-killed Anoplophora glabripennis larvae. The 348 Malpighian tubules emerge at the midgut/hindgut boundary, appear opaque (cloudy), and are 349 repeated curved (bumpy). Tracheae appear hollow, shiny, and smooth in appearance. Tracheae 350 and Malpighian tubules are similar in colour in freeze-killed specimens, but tubules are bright 351 yellow in colour in fresh-killed larvae. Scale bars are $0.2 \mathrm{~mm}$. 
353 Figure 6. Muscle. Musculature for both freeze-killed and fresh-killed Anoplophora glabripennis

354 larvae. A, Head and thorax; B, abdomen.

355

356 Figure 7. Supraoesophageal ganglia. The supraoesophageal ganglia (brain) of Anoplophora

357 glabripennis larvae lies dorsal to the oesophagus and ventral to the prothoracic muscle. The

358 ganglion lobes are easily distinguished from surrounding tissue in both frozen and fresh-killed

359 specimens. A, Frozen specimens, B) fresh-killed specimens.

360 